\title{
Aprendendo conceitos geográficos de maneira significativa e colaborativa com o auxilio das Tecnologias de Rede.
}

\author{
Ana Maria de Oliveira Pereira ${ }^{1}$ \\ Adriano Canabarro Teixeira ${ }^{2}$ \\ (ana.pereira@uffs.edu.br;teixeira@upf.br)
}

\begin{abstract}
This article is part of a Master's degree dissertation whose title is "The potential of networking technologies in the construction of geographical knowledge," which was held at the Post Graduation Program at Universidade de Passo Fundo and defended in 2010. In this dissertation a field research with students from the seventh grade of elementary school was performed, addressing the theme "landforms". In the present study, we will lead the possibility of meaningful learning in knowledge building mediated by networking technologies. For this purpose, some aspects of learning theories articulated to the construction of the geographical knowledge will be presented having the hypermedia as language and learning environment. Finally the results obtained from the analysis of the experience.
\end{abstract}

Keywords: learning, meaningful learning, knowledge, geographical knowledge and network technologies.

\section{Resumo}

Este artigo é parte da dissertação de mestrado intitulada "O potencial das tecnologias de rede na construção do conhecimento geográfico", realizada no PPGE da UPF, defendida em 2010, onde realizou-se uma pesquisa de campo com alunos do sétimo ano do ensino fundamental, abordando o tema "formas de relevo". No presente trabalho trataremos da possibilidade de aprendizagem significativa na construção do conhecimento mediada pelas tecnologias de rede. Para tal, serão apresentados alguns aspectos das teorias da aprendizagem articulada à construção do conhecimento geográfico tendo a hipermídia como linguagem e ambiente de aprendizagem e por fim os resultados obtidos a partir da análise da experiência.

Palavras-chave: aprendizagem, aprendizagem significativa, conhecimento, conhecimento geográfico e tecnologias de rede.

\subsection{Introdução}

Vivemos em uma sociedade permeada pela informação, por isso denominada "sociedade da informação". O acesso a estas informações ficou facilitado pelo advento das tecnologias da informação e comunicação, onde as pessoas podem acessar a

\footnotetext{
${ }^{1}$ Professora Assistente da Universidade Federal da Fronteira Sul UFFS - Campus Erechim - Práticas de Ensino em Geografia.

${ }^{2}$ Professor Dr. na Universidade de Passo Fundo.
} 
qualquer hora e em diversos suportes as informações que lhes são necessárias. Mas será que somente as informações são necessárias para a construção do conhecimento?

Entendemos que um dos grandes desafios da escola atualmente é gerenciar o grande fluxo de informações disponíveis e torná-las significativas (PEREIRA, TEIXEIRA,2011), apropriando-se de ferramentas para seleção das informações mais adequadas, proporcionando uma interação entre estas e os sujeitos que fazem parte do processo educativo, a fim de construir o conhecimento. Nessa perspectiva, entende-se que a escola precisa acompanhar as mudanças que acontecem na sociedade a qual está inserida, utilizando-se das ferramentas disponíveis como mediadoras de processos de aprendizagem, tornando-a mais significativa para o aluno. Conforme Ausubel, na interpretação de Moreira,

O problema, pois, da aprendizagem em sala de aula está na utilização de recursos que facilitem a captação da estrutura conceitual do conteúdo e sua integração à estrutura cognitiva do aluno, tornando o material significativo. (2005 p.37).

Estes recursos podem ser encontrados nas tecnologias de rede, que no presente texto passa a ser representado por TR, e se utilizadas de maneira adequada podem proporcionar uma aprendizagem mais significativa e também a construção do conhecimento de maneira colaborativa.

Objetivou-se neste artigo, apresentar uma proposta de aprendizagem significativa, sob uma ótica sócio-interacionista, apoiada na teoria vygotskyana, que concebe aprendizagem como processo que se relaciona com o desenvolvimento da pessoa e ocorre desde o seu nascimento. A interação social proporciona ao indivíduo aprendizado e isso despertará processos internos de desenvolvimento. "Assim, o aprendizado é um aspecto necessário e universal do processo de desenvolvimento das funções psicológicas culturalmente organizadas e especificamente humanas" (VYGOTSKY, 1998a, p.118).

Utilizaremos também conceitos embasados em Pozo e Ausubel para referenciar a aprendizagem significativa desenvolvida a partir de um ambiente permeado pela tecnologia. $\mathrm{O}$ artigo é parte da dissertação de mestrado, onde a atividade prática da pesquisa foi desenvolvida com uma turma de alunos do sétimo ano do ensino fundamental em uma escola privada do município de Erechim, RS. A pesquisa aconteceu no turno inverso às aulas regulares.

Inicialmente o artigo apresenta uma breve contextualização acerca da aprendizagem e construção do conhecimento apoiadas nas teorias dos autores acima citados. Após trata-se do tema aprendizagem mediada pelas tecnologias de rede, as possibilidades e a linguagem hipermídia, onde a pesquisa foi desenvolvida, por fim as conclusões obtidas na realização da atividade proposta aos alunos. Neste artigo não faremos uma comparação de experiências e sim um relato da atividade desenvolvida.

\subsection{Aprendizagem e o conhecimento.}

Concebemos aprendizagem como o processo pelo qual os indivíduos constroem novos conhecimentos e em consequência, mudam o comportamento. "Aprender implica mudar e a maior parte das mudanças em nossa memória precisa de certa quantidade de prática, aprender, principalmente de modo implícito ou deliberado, supõe um esforço que requer altas doses de motivação" (POZO, 2002, p.138). 
A aprendizagem, como atividade socialmente organizada, nasce nas primeiras organizações sociais, que ocorreram há mais ou menos 5.000 anos, na antiga Mesopotâmia. Pode-se traçar aí um processo histórico da revolução da aprendizagem, dividida em três grandes momentos, que fizeram com que houvesse uma maior disponibilização do conhecimento à população em geral. Conforme Pozo (2002), esses momentos foram:

- $1^{\text {a }}$ revolução cultural na aprendizagem: criam-se os primeiros sistemas de escrita, utilizados na principal atividade econômica da época - a agricultura. Eram usadas tabuinhas de cera para registrar as transações agrícolas. A partir daí, surge à necessidade de formar escritores, dando origem às primeiras escolas, que transformam a escrita em um grande recurso mnemônico. Sabe-se que a escrita demanda instrução - quem deseja dominar essa ferramenta precisa de alguém que o ensine. Nesse caso, conforme Pozo, tem-se uma aprendizagem reprodutiva, pois a escrita passa a ser o objetivo principal da educação formal. Nessa época ainda, o conhecimento não era disponível para todos, sendo detido apenas pela elite religiosa, que só aceitava o conhecimento religioso e as suas próprias interpretações como verdadeiras. Normalmente, os escritores eram também os leitores. Ou seja, os grandes líderes religiosos escreviam, pois a escrita era o recurso disponível para registrar a memória, e também liam e davam a sua interpretação à população.

- $2^{\mathbf{a}}$ revolução cultural - invenção da imprensa: começa a descentralização e a relativização do conhecimento. Nesse momento, o sujeito que escreve já não é mais necessariamente o sujeito que interpreta a escrita. Cada pessoa lê o texto no contexto em que ela está inserida, sendo que as interpretações são diferentes - o leitor, que anteriormente era um mero expectador, deixa de ser passivo e passa a ter suas próprias interpretações. Surgem aí grandes mudanças no entendimento da aprendizagem, pois não existem mais verdades absolutas, e o conhecimento vai gerando novos conhecimentos.

- $3^{a}$ revolução cultural - tecnologias da informação: marcada pelo grande fluxo de informações, algumas fragmentadas, confusas e às vezes até enganosas e sem autoria, a escola perde o papel central na transmissão da informação, pois ela está disponível a todos que tiverem acesso aos meios de disseminação: televisão, rádio, internet e outros. Nesse contexto, cabe ao indivíduo construir suas próprias verdades relativas, as quais lhe possibilitarão ser um membro ativo da sociedade em que vive.

O processo de evolução da aprendizagem humana nos mostra que o ser humano, a partir da invenção da imprensa, não usa mais um modelo único de aprendizagem, onde priorizava-se a memorização e a interpretação com base em um só autor. Atualmente sabe-se que é necessário diversificar maneiras de aprendizagem, apropriando-se dos mecanismos existentes e disponíveis para tal. O aluno hoje, tem condições de ser um agente ativo na construção do próprio saber (PEREIRA,TEIXEIRA, 2011).

Somos bombardeados diariamente com inúmeras informações, provenientes de diversas fontes e que podem ser acessadas em múltiplos suportes. Dado o contexto a escola tem papel significativo na transformação desse cabedal de informações em conhecimento, podendo elevar à categoria de sociedade da aprendizagem.

Neste momento histórico não se pode admitir uma aprendizagem meramente reprodutiva. Com as informações provenientes das mais variadas fontes, as pessoas terão de seleciona-las, sistematizá-las e estabelecer relações entre elas. "Para o homem contemporâneo, a informação é uma necessidade diária”(POZO, 2002). O autor compara a sociedade da informação às redes fast food, pois existe uma carga muito grande de informações disponíveis e é impossível armazenar tudo isso. Segundo o 
mesmo, sofre-se uma obesidade informativa, e é necessário uma dieta de informações, para diagnosticar quais as reais necessidades para a aprendizagem.

Nas TR é possível realizar, através de uma conexão, navegações infinitas em uma rede de informações, porém, é necessário organizar seus roteiros para que a navegação seja significativa. A lógica reticular das redes de informação pode proporcionam desvio de percurso, assim, são necessárias estratégias de seleção, relação e reelaboração das informações, afim de que possam ser transformadas em conhecimento, ou seja, sistematização, associação e internalização dessas informações. O conhecimento, enfim, é uma construção coletiva, é na interação das pessoas, em um determinado contexto social e cultural, que os indivíduos integrantes de um grupo se apropriam do conhecimento, internalizam e geram novos conhecimentos.

A escola tem papel fundamental na disponibilização de ferramentas e metodologias que proporcionem ao aluno a integração das aprendizagens adquiridas ao longo de sua vida social dando sentindo, interagindo e reelaborando saberes.

Para a efetivação do aprendizado é necessário uma integração entre as aprendizagens associativas e construtivas, pois ambas se complementam nas etapas da construção do conhecimento. Buscamos em Pozo e Ausubel a sustentação teórica para as definições, conforme Pozo a aprendizagem é associativa quando se estabelece relação entre fatos, comportamentos e informações e será significativa, quando é compreendido o significado do que está sendo estudado. Este significado será retirado da bagagem de conhecimentos dos indivíduos adquirida no decorrer da vida em sociedade. Para Ausubel, segundo interpretação de Moreira, 2005 "a aprendizagem significativa é um processo pelo qual uma nova informação se relaciona com um aspecto relevante da estrutura do conhecimento do indivíduo".

Entende-se também, que neste processo de construção do conhecimento a motivação é fator importante, pois, como visto anteriormente, aprender implica mudar, e mudanças exigem práticas, sendo que, para realização das práticas, é necessário que haja motivação.

A inserção dos meios tecnológicos presentes na sociedade às práticas pedagógicas pode proporcionar esta motivação, pois os alunos da sociedade da aprendizagem nasceram em uma era digital, sendo que uma grande parte deles é habituada a utilizar os recursos tecnológicos no seu dia a dia, podendo transpor a tecnologia da sua diversão para a construção do conhecimento sistematizado. Utilizando assim, os conhecimentos já adquiridos para dominar uma ferramenta, na construção de novos conhecimentos.

\subsection{Uma metodologia de ensino de geografia mediada pelas TR.}

Como visto anteriormente, a aprendizagem é um processo que está relacionado com o desenvolvimento do indivíduo e o acompanha desde o seu nascimento. Na convivência em sociedade, todo conhecimento que gerar mudanças de comportamento caracteriza-se como aprendizagem. A sociedade da aprendizagem evolui de maneira muito rápida no que diz respeito ao uso das TR no cotidiano. No trabalho, no lazer, na escola, enfim, em todas as atividades é possível utilizar essas tecnologias, as quais, em muitos casos, são imprescindíveis.

A evolução tecnológica proporciona a hibridização das tecnologias e linguagens em um mesmo ambiente - a hipermídia. A essa hibridização dá-se o nome de convergência das mídias. Sobre isso, Santaella diz: 


\begin{abstract}
A hipermídia mescla textos, imagens fixas e animadas, vídeos, sons, ruídos em um todo complexo. É essa mescla de vários setores tecnológicos e várias mídias anteriormente separadas e agora convergentes em um único aparelho, o computador, que é comumente referida como convergência de mídias. Sem essa convergência, a hipermídia, como linguagem híbrida, prototípica do mundo digital, não seria possível. (2007, p. 48).
\end{abstract}

Neste sentido, existe a possibilidade de desenvolver aulas que tratem de diversos assuntos, como conhecer e identificar as formas de relevo, por exemplo. Uma das ferramentas compatíveis com o assunto é o Google Earth ${ }^{3}$, que possibilita uma visualização do ambiente estudado, com possibilidade de aproximação e distanciamento, sobrevoo, observação de edificações, algumas em 3D, de ruas etc, permitindo, assim, uma visualização ampla do objeto de estudo desta pesquisa, neste caso, os tipos de relevo, como exemplificado abaixo.

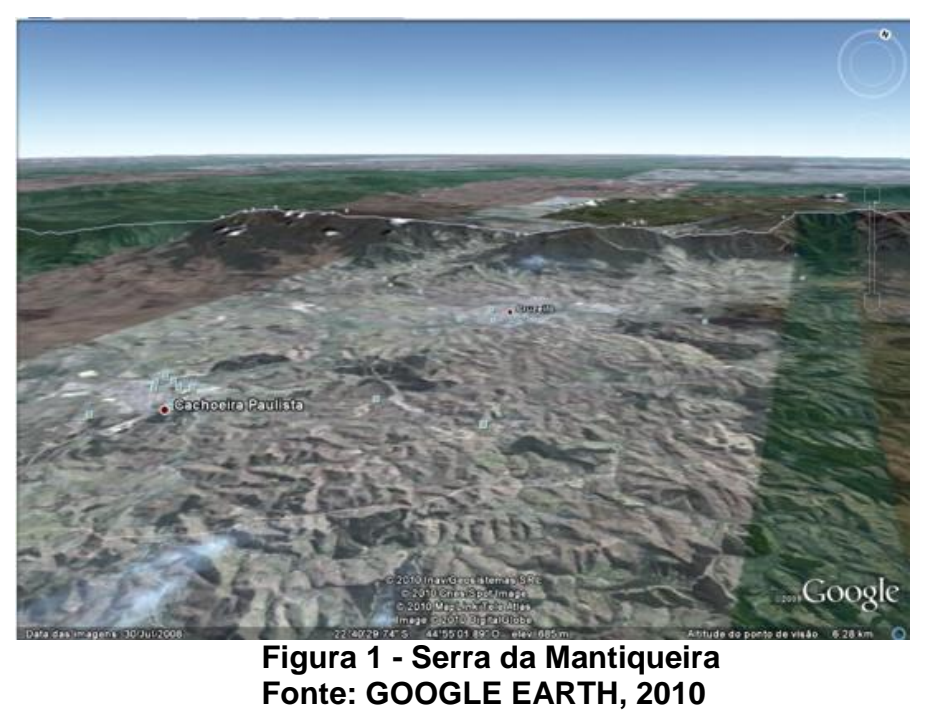

3 Google Earth (em português, Google Terra) é um programa desenvolvido e distribuído pelo Google, cuja função é apresentar um modelo tridimensional do globo terrestre, construído a partir de fotografias de satélite de fontes diversas, imagens aéreas (fotografadas de aeronaves) e GIS 3D. O programa pode ser usado simplesmente como um gerador de mapas bidimensionais e fotos de satélite ou como um simulador das diversas paisagens presentes no Planeta Terra. Com isso, é possível identificar lugares, construções, cidades, paisagens, entre outros elementos (WIKIPEDIA, 2010a). 


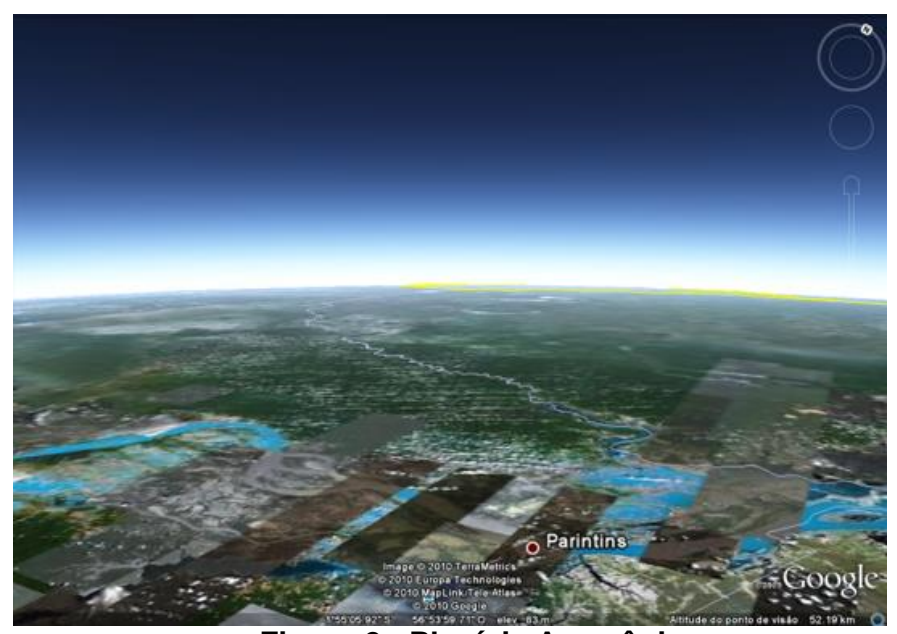

Figura 2 - Planície Amazônica

Fonte: GOOGLE EARTH, 2010

Para o trabalho com crianças do sétimo ano do ensino fundamental, utilizou-se principalmente a imagem, adotando-se o sistema de interpretação formulado por Robert William Ott no livro Ensinando crítica nos museus e adaptado ao trabalho de geografia mediado pelas TR, denominado Image Watching. Este sistema de interpretação objetiva incentivar o pensamento crítico a respeito das obras de arte e transformar os conceitos apreendidos dessa forma crítica voltada à produção criativa na aula de artes (1997, p. 128). O sistema é composto por cinco categorias a seguir apresentadas, tendo como base Ott (1997):

$1^{\mathrm{a}}$ - na categoria descrevendo, o aluno faz uma observação profunda e detalhada sobre a obra. $\mathrm{O}$ instrutor questiona, com o objetivo de fazer com que os alunos exteriorizem suas percepções e as partilhem com os outros componentes do grupo, ampliando suas percepções e também realizando a construção colaborativa do conhecimento. No caso do trabalho relatado neste artigo, a categoria se caracteriza da seguinte maneira: o aluno se expressa acerca de tudo o que vê nos recursos que está consultando.

$2^{\mathrm{a}}$ - a segunda categoria é o analisando, que proporciona o conhecimento mais profundo da obra, de detalhes, do design, de formas, que levarão à ideia que o artista quer transmitir com a imagem. No contexto deste trabalho, analisar-se-ão com mais atenção detalhes, formas, tipo de vegetação, existência ou não de ocupação humana e três elementos que não haviam sido observados na etapa anterior (descrevendo).

$3^{\mathrm{a}}$ - a categoria interpretando é considerada pelo autor como uma das mais criativas, pois proporciona ao participante expressar suas emoções por meio da observação. Nesta concepção de observação, a interpretação deve ser precedida de subsídios que sirvam como base à compreensão dos sentimentos pessoais elaborados nas categorias descrevendo e analisando. No presente trabalho, esta categoria implica verificar o que os alunos conseguem expressar sobre as formas relevo vistas. $\mathrm{O}$ pesquisador questiona sobre qual a relação entre o que o aluno observou e o conhecimento adquirido empiricamente, a partir das categorias anteriores (descrevendo e analisando).

$4^{\mathrm{a}}$ - a categoria fundamentando diz respeito à parte histórica da obra, através de pesquisas a respeito da obra, conversas com o artista, leituras em livros e catálogos e também vídeos. No caso da ampliação de conceitos geográficos, a categoria se organiza a partir das pesquisas que os alunos farão na web sobre o relevo, com vistas a entender o porquê das diferenças existentes.

$5^{\mathrm{a}}$ - a última categoria é a revelando, na qual o aluno mostra o que conheceu da obra, por meio de uma expressão artística. Ele criará uma nova obra a partir do que assimilou nas etapas anteriores. Dentro do escopo da pesquisa, nesta etapa o aluno expressou suas 
conclusões sobre os tipos de relevo vistos, utilizando-se de tecnologias como o Google docs para construir um texto colaborativo. Após, cada aluno elaborou uma apresentação em PowerPoint sobre o que entendeu através do sistema de interpretação proposto.

Cada categoria compreende uma preparação, conhecida como Thought Watching oportunidade em que o observador é orientado pelo instrutor do museu, através de um livro de exercícios elaborado pelo próprio estabelecimento, à interpretação visual e verbal das imagens observadas. Na adaptação para as aulas de geografia, o trabalho foi desenvolvido no laboratório de informática, utilizando-se das TR, sendo que a preparação para a observação foi orientada pela pesquisadora.

Partindo da análise das cinco categorias de interpretação, foram utilizadas as tecnologias disponíveis na internet para o desenvolvimento das aulas de geografia voltadas aos aspectos relativos ao relevo. Como citado anteriormente, a opção pela hipermídia como linguagem, foi devido à possibilidade de autonomia e também de interatividade, podendo assim proporcionar uma aprendizagem mais significativa.

\subsection{A utilização da hipermídia nas aulas de geografia}

Sendo a hipermídia uma linguagem que pelas suas características, proporciona uma maneira não linear e não sequencial de interpretar as informações, cada aluno, utilizando-se dessa ferramenta, poderá construir o conhecimento de maneira ativa em uma dinâmica de co-autoria. Deixando assim a condição de receptor passivo dos conteúdos e atingindo um nível de agente participativo nesta construção, pois terá condições de utilizar de maneira autônoma tudo o que a web disponibiliza, construindo a sua bagagem de conhecimento.

Para a leitura de imagens nas aulas de geografia em um espaço hipermidiático, o uso das categorias anteriormente citadas pode proporcionar uma maior interatividade entre aluno/professor, aluno/aluno, aluno/outros e aluno/conteúdo, evidenciando assim a construção colaborativa do conhecimento. Os questionamentos, as dúvidas, as conclusões foram socializados entre as pessoas que integravam o grupo e com interessados pelo assunto que encontravam-se em outros locais, geograficamente distantes, porém territorializados em um espaço comum: o ciberespaço ${ }^{4}$. A interatividade é ação indispensável na construção do conhecimento em espaços colaborativos, como refere Santaella:

Uma das características principais da tecnologia criada e distribuída em forma digital, potencializada pela configuração informacional em rede, é permitir que os meios de comunicação possam atingir os usuários e obter um feedback imediato. Por isso mesmo, há algum tempo, um dos tópicos centrais da comunicação digital tem sido a interatividade. Tendo em vista que a interação está na medula dos processos cognitivos ensejados pela comunicação em ambientes informacionais. (2007, p. 151).

O diagrama a seguir explica o processo de interação na construção do conhecimento geográfico mediado por computadores:

\footnotetext{
4 Realidade multidirecional, artificial ou virtual incorporada a uma rede global, sustentada por computadores que funcionam como meios de geração e acesso. Nessa realidade, da qual cada computador é uma janela, os objetos não são nem físicos nem, necessariamente, representações de objetos físicos, mas têm forma, caráter e ação de dados, informação pura. (SANTAELLA, 2007, p. 40).
} 


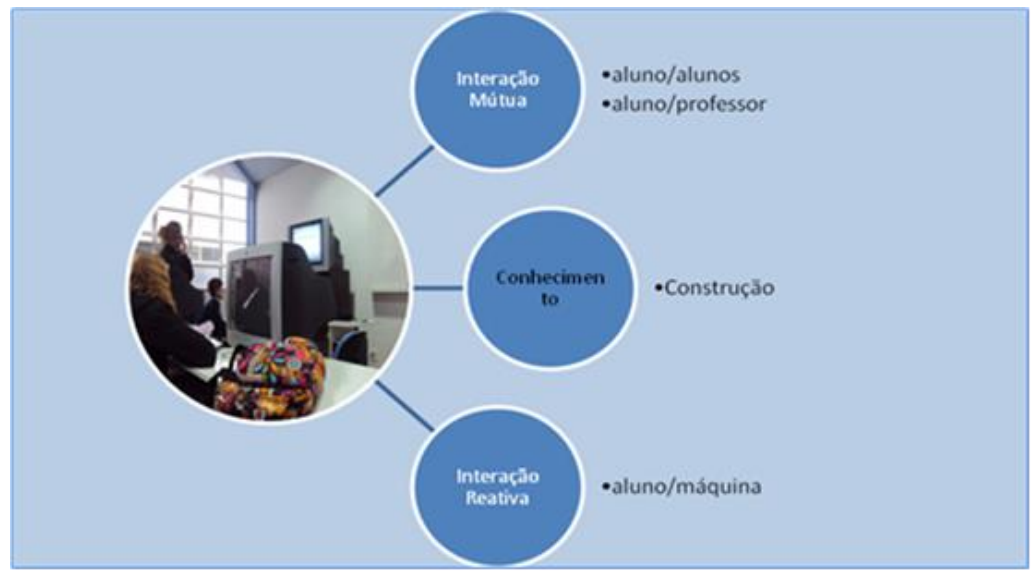

Figura 3 - Construção colaborativa do conhecimento geográfico

Fonte: Pereira A., 2010.

Sendo a aprendizagem um processo de interação social e o conhecimento originário da interação entre sujeito e objeto, a interatividade auxilia na construção do conhecimento, consistindo em uma forma de confrontar opiniões, suposições ou certezas sobre um determinado assunto no momento em que ele está sendo estudado. Dessa maneira entendemos que a mediação das TR no processo ensino aprendizagem é um espaço que proporciona uma aprendizagem significativa, pois além dos alunos estarem em um ambiente apreciado pelos mesmos, oportuniza a interação, que por sua vez tem uma capacidade grande de proporcionar a relação entre o novo e o conhecimento que já encontra-se na estrutura cognitiva de cada indivíduo.

\subsection{Considerações Finais}

Com a utilização dessa metodologia de pesquisa observou-se que os alunos demonstraram alguma dificuldade no início, para elaborar a definição de relevo e também em diferenciar os tipos de relevo existentes, apesar de o conteúdo ter sido trabalhado com eles em ambiente de sala de aula de maneira regular. Tiveram também um pouco de dificuldade no que diz respeito à autonomia, porém logo foi superado. Por esse motivo, foram retomados alguns tópicos, após o que, os alunos foram orientados a construir seus próprios conceitos referentes aos diferentes tipos de relevo, com o auxilio das TR. Para visualização dos diferentes tipos de relevo utilizou-se principalmente os recursos do Google Earth, onde é possível a visualização e simulação de um sobrevoo nos diferentes tipos de terrenos. Isso se deve à crença, de que, nas palavras de Garcia ( 2002), o conhecimento surge num processo de organização das interações entre o sujeito (o sujeito do conhecimento) e essa parte da realidade constituída pelos objetos (o objeto do conhecimento).

Dessa maneira, os alunos tiveram a possibilidade de associar o que eles já conheciam teoricamente às figuras que visualizavam e aos textos que encontraram. Eis a definição de planalto elaborada por uma das alunas participantes: "Planalto, no meu entendimento, é uma forma de relevo constituída por superfícies elevadas. Planalto é alto e pode ter locais planos, como também pode ter locais mais acidentados. Podemos também observar a capacidade de diferenciação dos tipos de relevo, apresentada por outro aluno do grupo, "As diferenças são: um é elevado, tem bastante altitude e tem bastante variação no solo (planaltos). O outro não tem muita elevação, mas é totalmente plano (planícies). E o outro é uma forma de relevo aplainado, onde podem ser encontradas baixas colinas". Dentro de uma linguagem simples, porém de sua 
autoria, também com alguns pequenos erros conceituais, que não comprometem o entendimento, os alunos fazem suas construções sobre os diferentes tipos de relevo, planaltos, planícies e depressões.

Alguns alunos tiveram mais dificuldades que os outros, o que ficou claro nas suas anotações no documento compartilhado e também nas revisões realizadas em cada início de aula da atividade de pesquisa. Um exemplo é a resposta do aluno L quando lhe foi solicitado que identificasse o tipo de relevo em que está localizada a capital do país, "Brasília está localizada em uma planície". Tal constatação corrobora o pensamento de Vygotsky (1998b), onde diz que não se ensina conceitos através de treinamentos, pois eles só podem ser elaborados quando o desenvolvimento mental da criança tiver atingido o nível necessário. Os alunos de uma mesma turma não constroem os seus conhecimentos ao mesmo tempo, cada um tem particularidades em suas construções. Nesse momento constata-se a fundamental importância do professor presente nas construções dos alunos é ele quem irá detectar interpretações equivocadas e orientar atividades para que os alunos possam apropriar-se significativamente dos conceitos científicos, podendo realizar as associações com os conhecimentos já adquiridos em outras oportunidades.

Assim, para que os alunos pudessem construir suas definições, a cada início de aula eles eram instigados a dar exemplos de cada tipo de conceito levantado. Dessa maneira, conseguiu-se observar, através dos relatos feitos em aula e das anotações no documento compartilhado, o desenvolvimento das atividades cognitivas de cada aluno a seu tempo, em anuência ao que defende Vygotsky (1998b), elaborando os conceitos a partir de seus conhecimentos prévios, tornando dessa maneira, a aprendizagem mais significativa.

A partir da análise da experiência, conclui-se que a utilização das TR como espaço de construção do conhecimento geográfico significativo proporciona ao aluno uma maior integração entre os conceitos científicos e o seu dia a dia. Com a possibilidade de visualização, ampliam-se as chances de interpretação e associação dos conceitos à vivência diária do aluno. Já com a interatividade - uma das características das TR-, a construção do conhecimento se torna muito mais colaborativa, proporcionando aos alunos mais autonomia e ao mesmo tempo maior socialização do conhecimento e das ferramentas que tornam esse processo possível.

\section{0 - Referências Bibliográficas}

GARCIA, Rolando. O conhecimento em construção: das formulações de Jean Piaget à teoria de sistemas complexos. Porto Alegre: Artmed, 2002.

MOREIRA, M. A. Aprendizagem significativa: um conceito subjacente. In: Encuentro Internacional sobre el aprendizaje significativo. Burgos: Serviço de Publicaciones de la Universidad de Burgos, 1997. Disponível em: <http://www.if.ufrgs.br/ moreira/ apsigsubport.pdf >. Acesso em 22 jul. 2010.

MOREIRA, M.A. MASSINI, E.F.S. Aprendizagem Significativa: A Teoria de David Ausebel. São Paulo: Centauro, 2005.

OTT, Robert William. Ensinando críticas nos museus. In: BARBOSA, Ana Mae (Org.). Arte-educação: leitura no subsolo. São Paulo: Cortez, 1997. 
PEREIRA,A.M.O. O potencial das Tecnologias de Rede na Construção do conhecimento Geográfico. Dissertação Mestrado em Educação - PPGE, Universidade de Passo Fundo - UPF, 2010

PEREIRA, A. M.O. TEIXEIRA, A.C. As Tecnologias de Rede como Espaço de Aprendizagens Significativas em Geografia. Anais do XVII Workshop de Informática na escola - WIE 2011, Aracaju- SE, p. 1157-1167.

POZO, Juan Ignácio. Aprendizes e mestres: a nova cultura da aprendizagem. Porto Alegre, RS: Artmed, 2002.

. Aquisição do conhecimento. Porto Alegre, RS: Artmed, 2005.

SANTAELLA, Lucia. Navegar no ciberespaço: o perfil do leitor imersivo. 2. ed. São Paulo: Paulus, 2007.

VYGOTSKY, Lev Semenovich. A formação social da mente. São Paulo: Martins Fontes, 1998a.

Pensamento e linguagem. São Paulo: Martins Fontes, 1998b.

WIKIPEDIA, A enciclopédia Livre. Google Earth. Disponível em: <http://pt.wikipedia.org/wiki/Google_Earth〉. Acesso em: 05 jan. 2010a.

. Google Maps. Disponível em: 〈http://pt.wikipedia.org/wiki/Googlemaps〉. Acesso em: 05 jan. 2010b. 